\title{
Effects of fibre content on mechanical properties and fracture behaviour of short carbon fibre reinforced geopolymer matrix composites
}

\author{
TIESONG LIN, DECHANG JIA*, MEIRONG WANG, PEIGANG HE and DEFU LIANG \\ Institute for Advanced Ceramics, Harbin Institute of Technology, Harbin 150001, People's Republic of China
}

MS received 2 June 2008

\begin{abstract}
Geopolymer matrix composites reinforced with different volume fractions of short carbon fibres $\left(\mathrm{C}_{\mathrm{f}} /\right.$ geopolymer composites) were prepared and the mechanical properties, fracture behaviour and microstructure of as-prepared composites were studied and correlated with fibre content. The results show that short carbon fibres have a great strengthening and toughening effect at low volume percentages of fibres (3.5 and $4.5 \mathrm{vol} . \%$ ). With the increase of fibre content, the strengthening and toughening effect of short carbon fibres reduce, possibly due to fibre damage, formation of high shear stresses at intersect between fibres and strong interface cohesion of fibre/matrix under higher forming pressure. The property improvements are primarily based on the network structure of short carbon fibre preform and the predominant strengthening and toughening mechanisms are attributed to the apparent fibre bridging and pulling-out effect.
\end{abstract}

Keywords. Short carbon fibre; mechanical properties; fracture behaviour; geopolymer; fibre content; composite.

\section{Introduction}

Short fibres are a kind of the most commonly used reinforcements to improve mechanical performance of ceramics, metals and polymers. Compared to continuous fibres reinforced composites, short fibres reinforced composites combine easier processability with low manufacturing cost. The most important factors that affect the short fibres reinforcement are fibre dispersion and fibre aspect ratio. Theoretically, the larger the fibre aspect ratio and the more uniform the distribution in matrix are, the more effective in securing toughness by its bridging and/or pull-out effect is. So, methods for obtaining homogeneous distribution of short fibres within matrix are important to obtain excellent mechanical properties.

At present, short fibres reinforced composites are often made with conventional techniques, including single or twin screw extruding (Li et al 2005), wet ball-milling mixing (Song et al 2002) and high-speed mechanical mixing methods (Mathew and Joseph 2007). However, the shear stresses exerted by screw or vane usually result in fibre aggregation or breakage ( $\mathrm{Fu}$ et al 2001; Liu and Liao 2004; Grande and Torres 2005), which is unfavourable to obtain reasonable microstructure and excellent mechanical properties.

\footnotetext{
*Author for correspondence (dcjia@hit.edu.cn)
}

Short fibres are also effective reinforcements in strengthening and toughening geopolymer materials. Short fibres, such as short polyvinyl alcohol (PVA) fibres (Liu et al 2005), short basalt fibres (Comrie and Kriven 2003), short Nextel 610 fibres (Zhao et al 2007) and short carbon fibres (Comrie and Kriven 2003), reinforced geopolymer composites have been prepared by conventional techniques and studied in the past. In this paper, a kind of sheet-like carbon fibre preforms prepared using $7 \mathrm{~mm}$ starting short carbon fibres with the help of ultrasonic scattering treatment was used to reinforce geopolymer matrix compo-

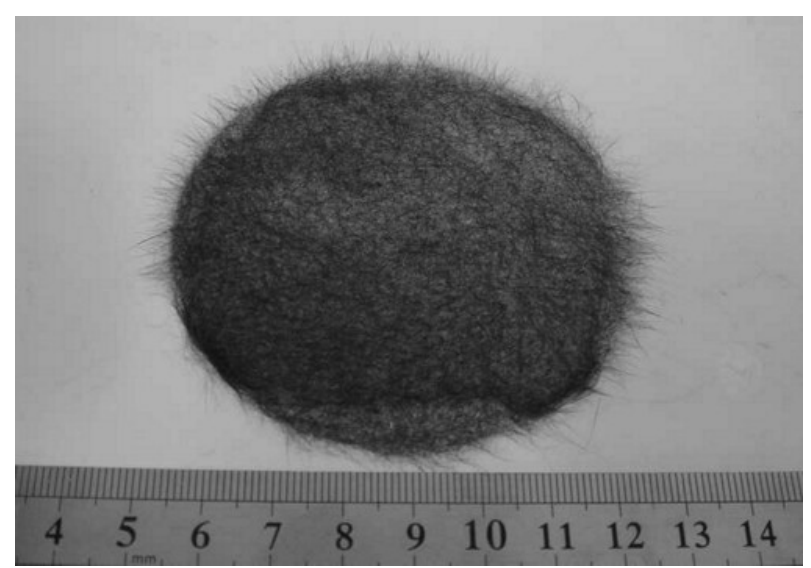

Figure 1. Optical image of as-prepared sheet-like short carbon fibre preform. 

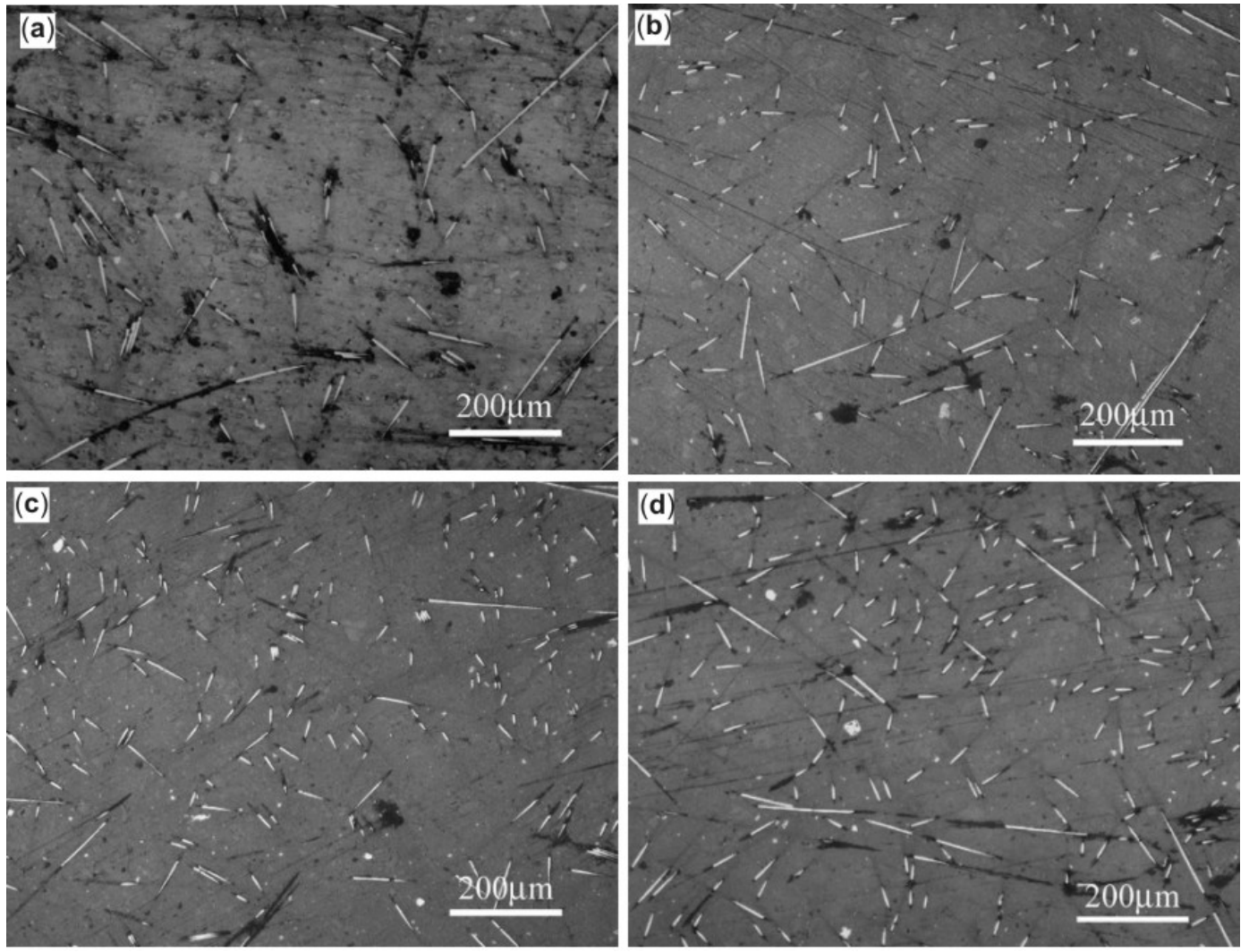

Figure 2. Surface micrographs parallel to the direction of lamination of composites a. 3.5 vol.\%, b. 4.5 vol. $\%$, c. 6 vol. $\%$ and d. 7.5 vol. $\% C_{\mathrm{f}}$ geopolymer.

Table 1. Properties of the as-prepared $\mathrm{C}_{\mathrm{f}}$ /geopolymer composites.

\begin{tabular}{|c|c|c|c|c|}
\hline Materials & $\begin{array}{l}\text { Density } \\
\left(\mathrm{g} / \mathrm{cm}^{3}\right)\end{array}$ & $\begin{array}{c}\text { Flexural strength } \\
(\mathrm{MPa})\end{array}$ & $\begin{array}{l}\text { Work of fracture } \\
\qquad\left(\mathrm{J} / \mathrm{m}^{2}\right)\end{array}$ & $\begin{array}{l}\text { Young's modulus } \\
\text { (GPa) }\end{array}$ \\
\hline Geopolymer & 1.42 & $16 \cdot 8 \pm 0 \cdot 7$ & $54 \cdot 2 \pm 4 \cdot 6$ & $8.61 \pm 0.43$ \\
\hline 3.5 vol. $\% C_{\mathrm{f}} /$ geopolymer & 1.42 & $91 \cdot 3 \pm 1 \cdot 3$ & $6435 \cdot 3 \pm 319 \cdot 9$ & $4.74 \pm 0.63$ \\
\hline 4.5 vol. $\% C_{\mathrm{f}} /$ geopolymer & 1.49 & $96 \cdot 6 \pm 4 \cdot 9$ & $5915 \cdot 2 \pm 151 \cdot 2$ & $12 \cdot 04 \pm 0.45$ \\
\hline 6 vol. $\% C_{\mathrm{f}} /$ geopolymer & $1 \cdot 56$ & $87 \cdot 4 \pm 4 \cdot 5$ & $3926 \cdot 3 \pm 116 \cdot 2$ & $20 \cdot 46 \pm 1 \cdot 61$ \\
\hline 7.5 vol. $\% C_{\mathrm{f}} /$ geopolymer & 1.67 & $42 \cdot 0 \pm 6 \cdot 1$ & $805 \cdot 7 \pm 49 \cdot 9$ & $17.77 \pm 0.78$ \\
\hline
\end{tabular}

sites. Geopolymer matrix composites reinforced with different volume fractions of short carbon fibres were prepared and the effects of fibre content on the mechanical properties, fracture behaviour and microstructure of as-prepared composites were investigated.

\section{Experimental}

The geopolymer resin used here has a composition with $\mathrm{SiO}_{2} / \mathrm{Al}_{2} \mathrm{O}_{3}=4, \mathrm{~K}_{2} \mathrm{O} / \mathrm{SiO}_{2}=0.3$ and $\mathrm{H}_{2} \mathrm{O} / \mathrm{K}_{2} \mathrm{O}=11$ (mole ratio), as described in the literature (Kriven et al 2003). A typical processing route for geopolymer resin is as follows: a potassium silicate solution was made by dissolving silica sol into a $\mathrm{KOH}$ solution with a magnetic stirrer. Kaolin powder $(4.08 \mu \mathrm{m}$ in average diameter) was calcined at $800^{\circ} \mathrm{C}$ for $2 \mathrm{~h}$ in order to obtain metakaolin powder.
The metakaolin powder was then added to the potassium silicate solution and mixed for $30 \mathrm{~min}$ with a high-shear mixer.

Starting short carbon fibres used for preparing preforms have an average length of $7 \mathrm{~mm}$. They were first separated by an ultrasonic vibrator in ethanol, and then filtered out by a wire sieve to form sheet-like short carbon fibre preform with a thickness within the range of $0 \cdot 15$ $0.2 \mathrm{~mm}$, as shown in figure 1. The obtained preforms were impregnated with geopolymer resin in a plastic container and laid together one by one to get a stack consisting of 20-50 layers of short fibre preforms. The plastic container with preform laminates was introduced into a vacuum bag and cured at $80^{\circ} \mathrm{C}$ for $24 \mathrm{~h}$. At the early stage of curing, a pressure of $0,0.2,1.2$ or $2.0 \mathrm{MPa}$ was loaded in order to obtain composites reinforced with different volume fractions of short carbon fibres (from $3 \cdot 5 \sim$ 
7.5 vol.\%). The redundant geopolymer resin was removed from the plastic container during the loading process and a final thickness of $5 \mathrm{~mm}$ for the preform laminates was obtained as the load was removed from the vacuum bag. The $C_{\mathrm{f}} /$ geopolymer composites were taken out from the vacuum bag and dried for an additional $24 \mathrm{~h}$ at $120^{\circ} \mathrm{C}$.

Flexural strength measurements were conducted on specimens $\left(4 \times 3 \times 36 \mathrm{~mm}^{3}\right)$ using a three point bend fixture on an Instron-500 testing machine with a span length of $30 \mathrm{~mm}$ at a crosshead speed of $0.5 \mathrm{~mm} / \mathrm{min}$. All flexural bars were machined with the tensile surface perpendicular to the direction of lamination. Load-displacement curves were recorded. Work of fracture was calculated by the area between load curves and $\mathrm{X}$ axis in the load/ displacement curves till the load dropped to $90 \%$ of the maximum load. Six specimens were tested under each test condition. Surface micrographs of the $\mathrm{C}_{\mathrm{f}}$ /geopolymer

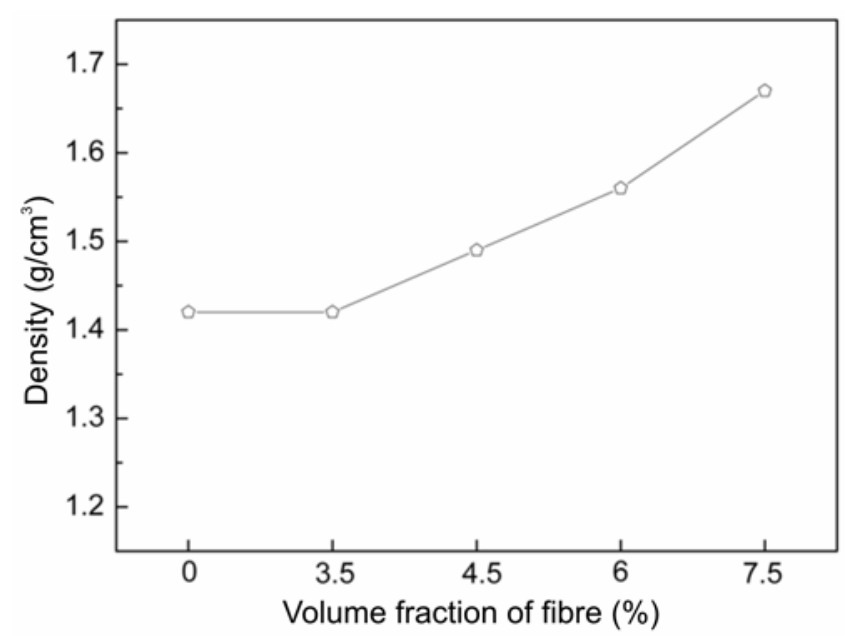

Figure 3. Density of $\mathrm{C}_{\mathrm{f}} /$ geopolymer composites with different fibre contents.

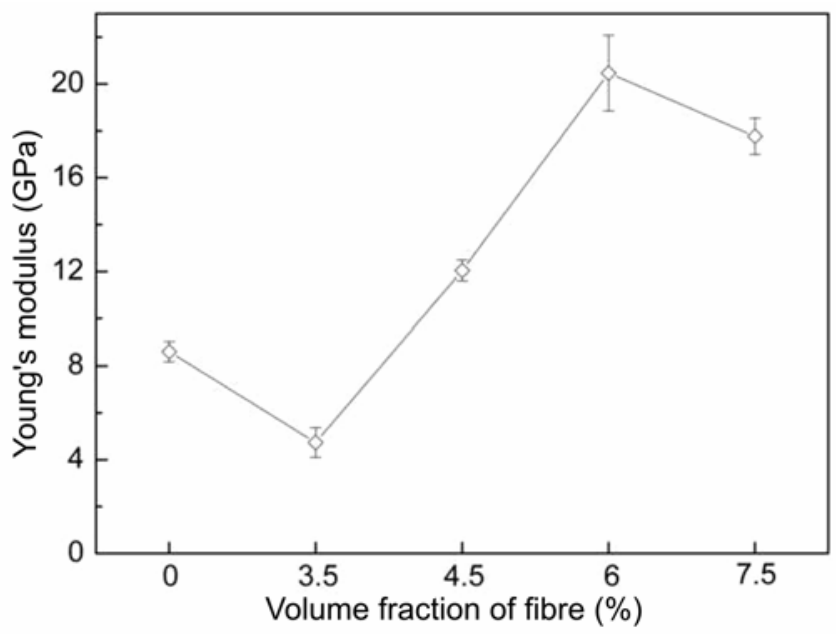

Figure 4. Variation of Young's modulus of $\mathrm{C}_{\mathrm{f}}$ /geopolymer composites as a function of volume fraction of short carbon fibre. composites were observed by optical microscope. Fracture surfaces of the composites were observed by scanning electron microscopy.

\section{Results and discussion}

The starting carbon fibres possess a high aspect ratio (about 1000), therefore, they tend to twist. In this experiment, the short carbon fibre preform preparation method with the help of the ultrasonic scattering treatment can effectively prevent fibres from too much aggregation as indicated in figure 1. As a result, the short carbon fibres have a relatively uniform distribution in geopolymer matrix for all the cases as shown in figure 2 .

Table 1 shows the properties of the as-prepared $\mathrm{C}_{\mathrm{f}} /$ geopolymer composites. The densities of composites gradu-

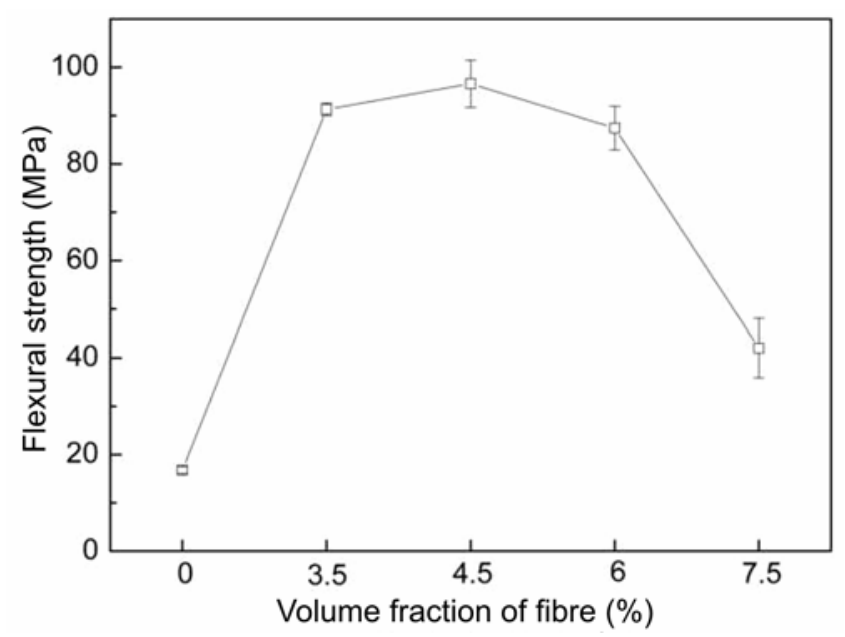

Figure 5. Variation of flexural strength of $\mathrm{C}_{\mathrm{f}}$ /geopolymer composites as a function of volume fraction of short carbon fibre.

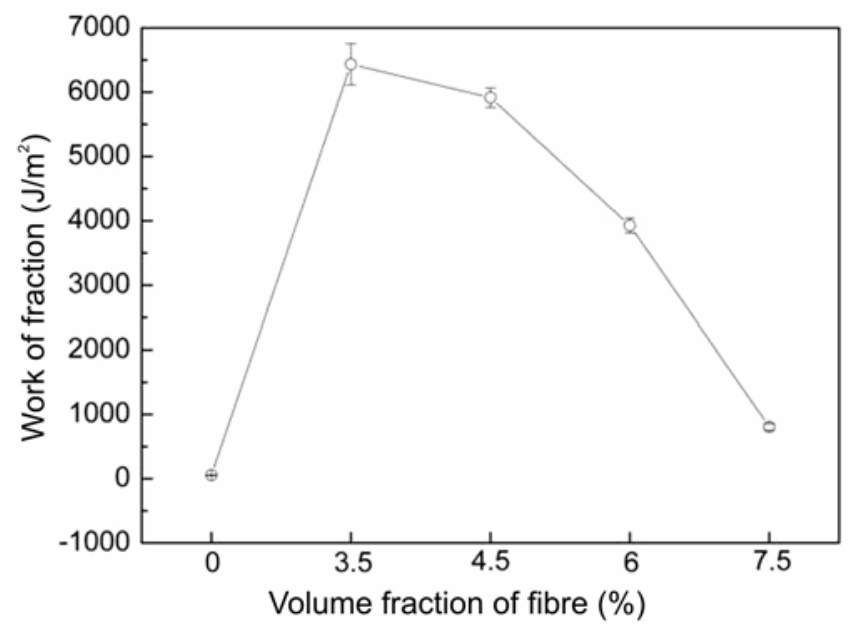

Figure 6. Variation and work of fracture of $\mathrm{C}_{\mathrm{f}}$ /geopolymer composites as a function of volume fraction of short carbon fibre. 
ally increase with the increase of volume fraction of short carbon fibres as shown in figure 3. This is due to the fact that carbon fibre has a higher density than geopolymer matrix does; on the other hand, density of the geopolymer matrix in $\mathrm{C}_{\mathrm{f}}$ /geopolymer composites improved under an increased forming pressure during curing. It is well known that the microstructure of geopolymer matrix has particulate features and pores which are of the order of $5 \sim 10 \mathrm{~nm}$ (Kriven et al 2007). Increasing of forming pressure during curing will undoubtedly reduce the size and scale of pores. The Young's modulus of composites is increased by the influence of fibre addition and pressure, as shown in figure 4 . However, the Young's modulus of 3.5 vol. $\% \mathrm{C}_{\mathrm{f}} /$ geopolymer composites prepared without pressure is unexpectedly lower than that of geopolymer matrix, which seems to be contradictory to the greatly improved flexural strength, as shown in table 1. The inconsistency may be attributed to the special network structure of short carbon fibres, the existence of some microcracks in the matrix and the lower relative density of the composites. However, accurate reasons result in the decrease of Young's modulus of 3.5 vol. $\% \mathrm{C}_{\mathrm{f}} /$ geopolymer composites which are far from understandable from this study and further analysis is needed.

The three-point bending strength of the composites as a function of volume fraction of short carbon fibres is shown in figure 5 . The flexural strength of the composites increases with the increase of volume fraction of carbon fibres from $3.5-4.5 \mathrm{vol} \%$. The addition of $4.5 \mathrm{vol} . \%$ short carbon fibres increases the geopolymer matrix strength from 16.8 to $96.6 \mathrm{MPa}$ (4.75 times higher), which is regarded as a great strengthening effect for such a low volume percentage of short carbon fibres. However, the strengthening effect of short carbon fibres reduces with a further increase in the fibre volume fraction to $6 \%$ and $7 \cdot 5 \%$. A similar trend for the work of fracture of the composites is shown in figure 6 . The work of fracture shows the maximum value (118 times higher than that of geopolymer matrix) at 3.5 vol. $\% C_{\mathrm{f}}$ /geopolymer composite, and then it gradually reduces with the increase of fibre volume content.

Network structure of short carbon fibre preform may be considered as integrity by interaction between fibres to strengthen and toughen the geopolymer materials. The destruction of this kind of composite is more difficult than that of composites reinforced with aligned short fibres under the same load due to the more reasonable interaction between fibres. Thus, $C_{\mathrm{f}}$ /geopolymer composites show so good a strengthening and toughening effect for such lower fibre percentages $(3.5 \mathrm{vol} . \%$ and $4.5 \mathrm{vol} . \%)$. The $\mathrm{C}_{\mathrm{f}}$ /geopolymer composites with higher fibre content are obtained by improving the forming pressure. Shear stresses at intersect between fibres exerted by higher forming pressure (1.2 and $2 \mathrm{MPa}$ ) possibly result in destruction of network structure of short carbon fibres due to fibre breakage or damage, which has a negative effect on short fibre reinforcement. The fact that the increase of the volume fraction of short carbon fibres by increasing the forming pressure is against the decrease of the mechanical properties indicates that keeping the short carbon fibres network structure integrity may be more important than increasing the volume fraction of short carbon fibres to improve the mechanical properties. Though the volume fraction of short carbon fibres is less at the lower forming pressure, may be it is suitable for production of better reinforcement in $\mathrm{C}_{\mathrm{f}}$ /geopolymer composites.

Typical load/displacement curves of matrix and composites are shown in figure 7. The low fracture energy of geopolymer matrix results in apparent catastrophic failure. In contrast, the failure of the $\mathrm{C}_{\mathrm{f}}$ /geopolymer composites is quite different. It can be seen that the composites extend elastically at the beginning of the test. Beyond the elastic limit, the applied load produces plastic deformation until maximum load is reached, and then the load drops with the increase of displacement and formed a long tail due to the fibre debonding and pulling-out. With the increase of volume fraction of short carbon fibres, the displacement of the crosshead shortens where the maximum applied load is reached and the load reduces fast during the unload process. This implies that the deformation and safety factors of the $\mathrm{C}_{\mathrm{f}} /$ geopolymer composites during service both decrease with the increase of volume fraction of short carbon fibres.

The fracture behaviour of the investigated composites can be seen clearly from the observation of the micrographs perpendicular to the fracture surface of $\mathrm{C}_{\mathrm{f}}$ /geopolymer composites, as shown in figure 8. A lot of fibre pulling-outs are found on the fracture surface. The pulling-out length is so big that it ensures the reinforcement of short carbon fibres effective in preventing catastrophic fracture. The pulling-out length of fibre decreases from 600-100 $\mu \mathrm{m}$ with the increase of volume fraction of short

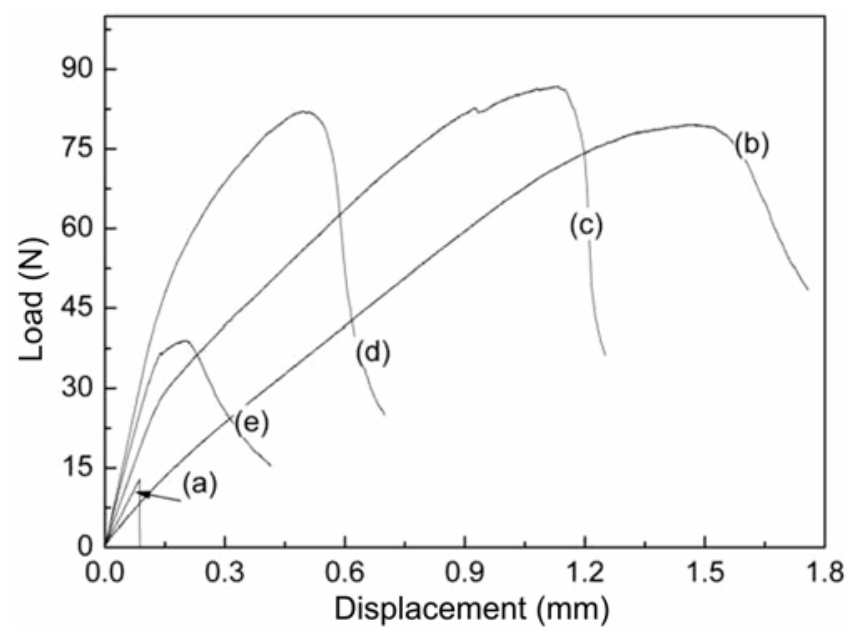

Figure 7. Load/displacement curves for (a) geopolymer matrix and (b) 3.5 vol.\%, (c) 4.5 vol.\%, (d) 6 vol.\% and (e) $7 \cdot 5$ vol. $\% \mathrm{C}_{\mathrm{f}}$ /geopolymer composites. 

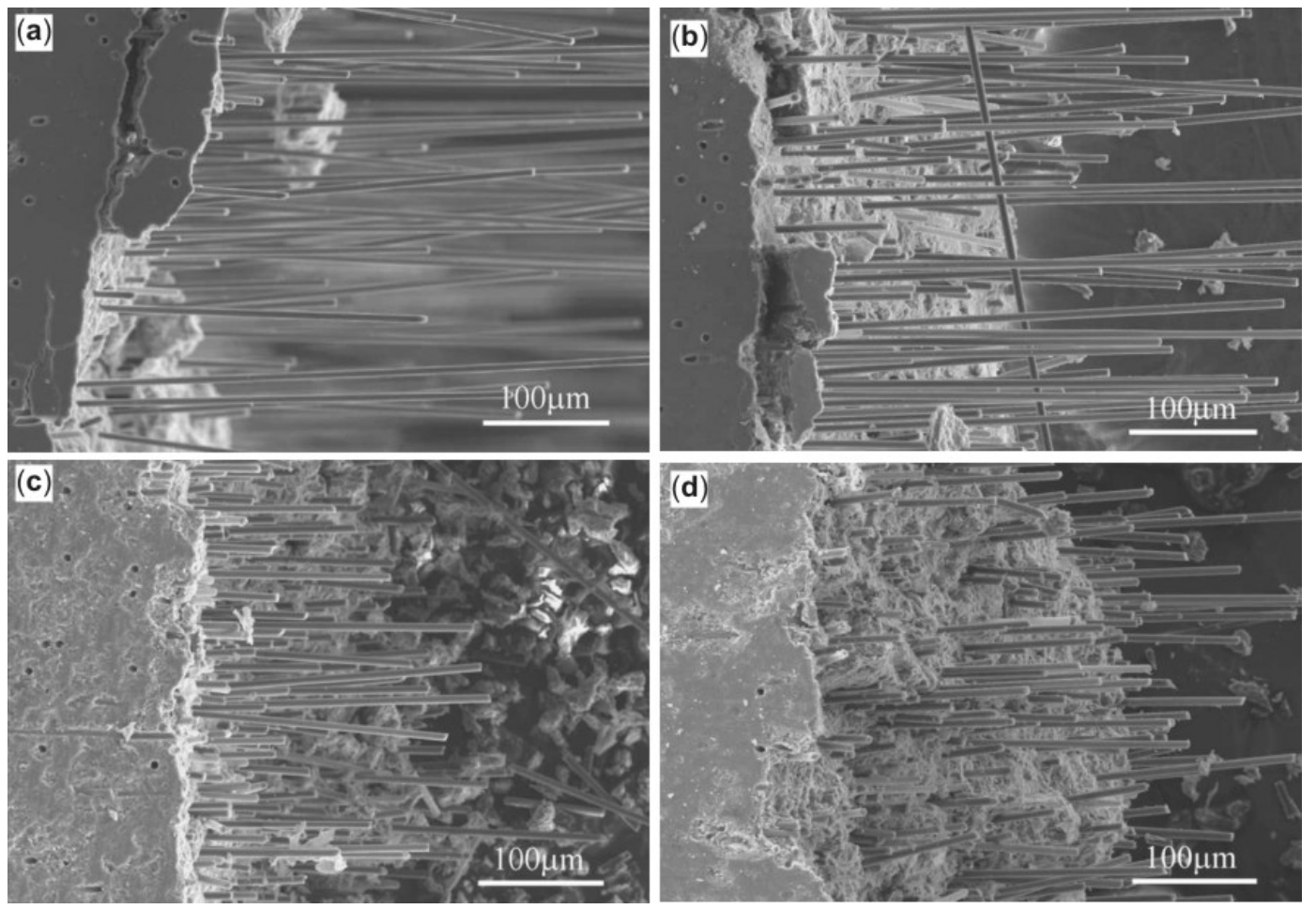

Figure 8. Scanning electron micrographs of perpendicular to the fracture surface and parallel to direction of lamination of a. 3.5 vol. $\%$, b. 4.5 vol. $\%$, c. 6 vol. $\%$ and d. 7.5 vol. $\% \mathrm{C}_{\mathrm{f}} /$ geopolymer composites.

carbon fibres from $3 \cdot 5-7.5$ vol.\%. The decrease of pulling-out length is due to the fact that higher shear stresses at intersect between fibres and interface cohesion strength of fibre/matrix formed by higher forming pressure make the fibres favour breakage rather than pulling-out during load. Fibre pulling-out absorbs more energy than fibre breakage (Mulligan et al 2003). This indicates energy consumption and the work of fracture decreases with the increase of volume fraction of short carbon fibres, which matches the results mentioned above.

\section{Conclusions}

Geopolymer matrix composites reinforced with different volume fractions of short carbon fibres were successfully prepared. The short carbon fibres are homogeneously distributed within the geopolymer matrix. Short carbon fibre preform shows a great strengthening and toughening effect for a low volume percentage of fibres (3.5 vol.\% and $4.5 \mathrm{vol} . \%)$. Although short carbon fibre content is increased under higher forming pressure, the strengthening and toughening effect of short carbon fibres reduces possibly due to fibre damage, formation of high shear stresses of intersect between fibres and strong interface cohesion of fibre/matrix. The predominant strengthening and toughening mechanisms are attributed to the reasonable network structure of short carbon fibres as well as the apparent fibre bridging and pulling-out.

\section{Acknowledgements}

This work was supported by the Program for New Century Excellent Talents in University (NCET, Grant No. NCET-04-0327), Program of Excellent Team in Harbin Institute of Technology and the Science Fund for Distinguished Young Scholars of Heilongjiang Province.

\section{References}

Comrie D C and Kriven W M 2003 Ceram. Trans. 153 211

Fu S Y, Lauke B, Mäder E, Yue C Y, Hu X and Mai Y W 2001 J. Mater. Sci. 361243

Grande C and Torres F G 2005 Adv. Polym. Technol. 24145

Kriven W M, Bell J L and Gordon M 2003 Ceram. Trans. 153 227

Kriven W M, Gordon M and Bell J L 2007 http://kriven.mse. uiuc.edu/recent/ recent.htm

Li Z J, Zhang Y S and Zhou X M 2005 J. Mater. Civ. Eng. 17 624

Liu H and Liao K 2004 J. Appl. Polym. Sci. 94211

Mathew L and Joseph R 2007 J. Appl. Polym. Sci. 1031640

Mulligan D R, Ogin S L, Smith P A, Wells G M and Worrall C M 2003 Compos. Sci. Technol. 63715

Song G M, Li Q, Wen G W and Zhou Y 2002 Mater. Sci. Eng. A326 240

Zhao Q, Nair B, Rahimian T and Balaguru P 2007 J. Mater. Sci. 423131 